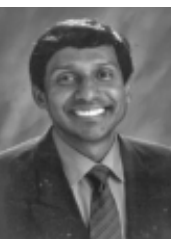

Buddhima Indraratna Professor of Civil Enginee Frofessor of Civil Engin Faculty of Engineering, Australia
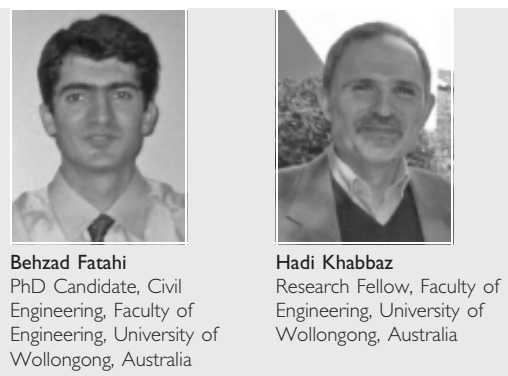

\title{
Numerical analysis of matric suction effects of tree roots
}

B. Indraratna PhD, DIC, MSc, FIEAust, FASCE, B. Fatahi MSc and H. Khabbaz MSc, PhD, MIEAust

The use of native vegetation in the coastal regions of Australia has become increasingly popular for stabilising railway corridors built over expansive clays and compressive soft soils. The tree roots provide three stabilising functions: (a) they reinforce the soil; (b) they dissipate excess pore pressures; and (c) they establish sufficient matric suction to increase the shear strength. The matric suction generated within the tree root zone propagates radially into the soil matrix, as a function of the moisture content change. Considering soil conditions, the type of vegetation and atmospheric conditions, a mathematical model for the rate of root water uptake is developed. A conical shape is considered to represent the geometry of the tree root zone. Based on this model for the rate of root water uptake, the pore water pressure distribution and the movement of the ground adjacent to the tree are numerically analysed. Field measurements taken from the previously published literature are compared with the authors' numerical predictions. It is found that, given the approximation of the assumed model parameters, the agreement between the predicted results and field data is still promising. The study indicates that native vegetation improves the shear strength of the soil by increasing the matric suction, and also curtails soil movements.

\section{NOTATION}

a Empirical coefficient

$C_{c} \quad$ Compression index

$C_{s} \quad$ Swelling index

$\mathrm{d} e^{\mathrm{el}} \quad$ Change of void ratio in the soil element

$\mathrm{d} p$

$E_{\mathrm{P}}$

$E T_{\mathrm{P}}$

$f(\psi)$

G
$k_{S}$ $n$ $p_{0}$ PI $r_{0}$

$R_{n}$

$S(x, y, z, t) \quad$ Root water uptake at point $(x, y, z)$ at time $\mathrm{t}$

$S_{\max } \quad$ Maximum rate of root water uptake

$S_{r} \quad$ Degree of saturation

$T(t) \quad$ Transpiration rate at time $t$

$T_{\mathrm{P}} \quad$ Potential transpiration

$u_{\mathrm{a}} \quad$ Pore air pressure

$u_{\mathrm{w}} \quad$ Pore water pressure

$V \quad$ Total volume

$V_{\mathrm{w}} \quad$ Volume of water

$w \quad$ Fraction of soil passing sieve \#200

$W \quad$ Dimensionless weighted function

z Vertical coordinate

$z_{0} \quad$ Vertical coordinate of maximum root density point

$\beta(x, y, z, t) \quad$ Root density

$\beta_{\max }(t) \quad$ Maximum root density at time $t$

$\chi \quad$ Effective stress parameter

$\delta_{i j} \quad$ Kronecker's delta

$\sigma_{i j} \quad$ Total stress in the porous medium

$\sigma_{i j}^{\prime} \quad$ Effective stress in the porous medium

$\theta \quad$ Volumetric moisture content

$\psi \quad$ Matric suction

$\psi_{\text {an }} \quad$ Lowest value of $\psi$ at $S=S_{\max }$

$\psi_{\mathrm{d}} \quad$ Highest value of $\psi$ at $S=S_{\max }$

$\psi_{\mathrm{w}} \quad$ Soil suction at wilting point

$\nabla \quad$ Divergence vector

\section{INTRODUCTION}

Apart from providing natural soil reinforcement, tree roots dissipate excess pore water pressure and produce sufficient matric suction to increase the shear strength of the surrounding soil. For these reasons, various forms of native vegetation are becoming increasingly popular in Australia for stabilising soft soils. It is well recognised that vegetation has various mechanical and hydrological effects on ground stability. Most attempts to quantify these effects have focused on the mechanical strengthening provided by the roots, but ignore the implications of evapotranspiration for the soil pore water pressure. For instance, the models developed by Chok et al., ${ }^{1}$ 
Operstein and Frydman, ${ }^{2}$ and Docker and Hubble ${ }^{3}$ consider the reinforcement effect of roots as a mechanism for increasing soil cohesion. However, the root-based soil suction changes were not considered in detail in their models. In order to quantify pore pressure dissipation and induced matric suction, the complex inter-relationships among the soil, plant and atmosphere should be analysed.

The loss of moisture from the soil may be categorised as: (a) water used for metabolism in plant tissues; and (b) water transpired to the atmosphere. However, as suggested by Radcliffe et al., ${ }^{4}$ the volume of water required for photosynthesis or metabolism in plant tissues compared with the total water uptake by roots is negligible. The total transpiration can then be assumed to be the same as the water uptake through the root zone.

Clearly, soil conditions (soil suction, hydraulic conductivity and penetration resistance), the type of vegetation (root distribution, the relative proportion of active roots and leaf area) and atmospheric conditions (net solar radiation, temperature, humidity, etc.) affect the rate of root water uptake, and hence transpiration. To formulate a comprehensive equation for calculating the rate of root water uptake, the interaction between the above features should be taken into account. However, owing to the complexity of this problem, some of the above features are simplified by the authors, as summarised below.

(a) As the potential transpiration rate (potential water discharge rate) is used instead of the difference between the water potential of root and soil, the hydraulic conductivity is not directly included in the transpiration rate.

(b) The penetration resistance of the soil influences root distribution; however, this effect is considered only indirectly through the root distribution effect.

(c) In the assessment of water uptake rate, the active roots are the most important: thus their relative proportion is considered in the root distribution effect.

(d) As the potential transpiration rate relates to the interaction between the atmosphere and foliage, the leaf area (canopy) is included in the potential transpiration. The influences of net solar radiation, air density, temperature and humidity changes are ignored in the model proposed by the authors.

In brief, the three independent features that are considered in detail in the root water uptake model are soil suction, root distribution and potential transpiration. In order to establish a rigorous formula for estimating the actual transpiration or root water uptake, the abovementioned factors have been quantified through relevant equations in the development of the proposed root water uptake model. In this study, a finite element analysis is employed to predict the soil suction profile and the associated ground surface settlement, based on the proposed governing equations. The FEM results are then compared with three published case studies to verify the numerical predictions.

\section{CONCEPTUAL DEVELOPMENT}

The key variable for estimating the transpiration rate is the rate of root water uptake, which depends on the geological, hydrological and meteorological conditions. Fig. 1 shows a schematic illustration of the soil-plant-atmosphere interaction. The rate of transpiration depends on the rate of root water uptake:

\begin{tabular}{|l|l|}
\hline $\mathrm{I}$ & $T(t)=\int_{V(t)} S(x, y, z, t) \mathrm{d} V$ \\
\hline
\end{tabular}

where $T(t)$ is the transpiration rate at time $t ; S(x, y, z, t)$ is the root water uptake at point $(x, y, z)$ at time $t$; and, if $V(t)$ is the volume of root zone at time $t, \mathrm{~d} V$ denotes a small volumetric change.

The details of each single root and its interaction with the surrounding soil are required to identify the microscopic interaction between the soil and the root system. A macroscopic approach is adopted in this study, which considers the integrated properties of the entire root system, assuming that both soil and roots are continuous media. Therefore the root water uptake is considered as a volumetric sink term in the flow continuity equation, which can be defined as the volume of water extracted per unit bulk volume of soil per unit time. The soil water flow differential equation, including the sink term, $S(x, y, z, t)$, can then be written as

\begin{tabular}{|l|l|}
\hline 2 & $\frac{\partial \theta}{\partial t}=\nabla \cdot(k \nabla \psi)-\frac{\partial k}{\partial z}-S(x, y, z, t)$ \\
\hline
\end{tabular}


where $\theta\left(=V_{\mathrm{w}} / V\right)$ is the volumetric moisture content $\left(V_{\mathrm{w}}=\right.$ volume of water, $V=$ total volume); $\nabla$ is the divergence vector; $\psi$ is the soil suction; $k$ is the hydraulic conductivity; and $z$ is the vertical coordinate (downward is positive).

\section{I. Soil suction}

Soil suction resists water movement and affects the transpiration rate: the greater the soil suction, the more difficult it becomes for the soil water to be discharged by the roots. Soil suction is a reduction factor for the potential transpiration rate, and as a general algebraic expression, the root water uptake can be written as a function of the maximum possible root water uptake, $S_{\max }$, and matric suction, $\psi$ :

As suggested by Feddes et al. ${ }^{5}$ the implicit function, $g\left(\psi, S_{\max }\right)$ can be expressed as two separate functions:

$S(x, y, z, t)=S_{\max }(x, y, z, t) f(\psi)$

where $f(\psi)$ is the root water uptake reduction factor as a function of matric suction.

To calculate $f(\psi)$, different approaches have been recommended by researchers. The equation suggested by Feddes et al., ${ }^{6}$ which is a simple and appropriate formula ${ }^{7}$ to determine soil suction effects, is used in this study. Various other equations proposed for $f(\psi)$ are given in Table 1 . The relationship between water uptake and soil suction suggested by Feddes et $a l .{ }^{6}$ is shown in Fig. 2. Referring to this figure, $f(\psi)$ can be written as

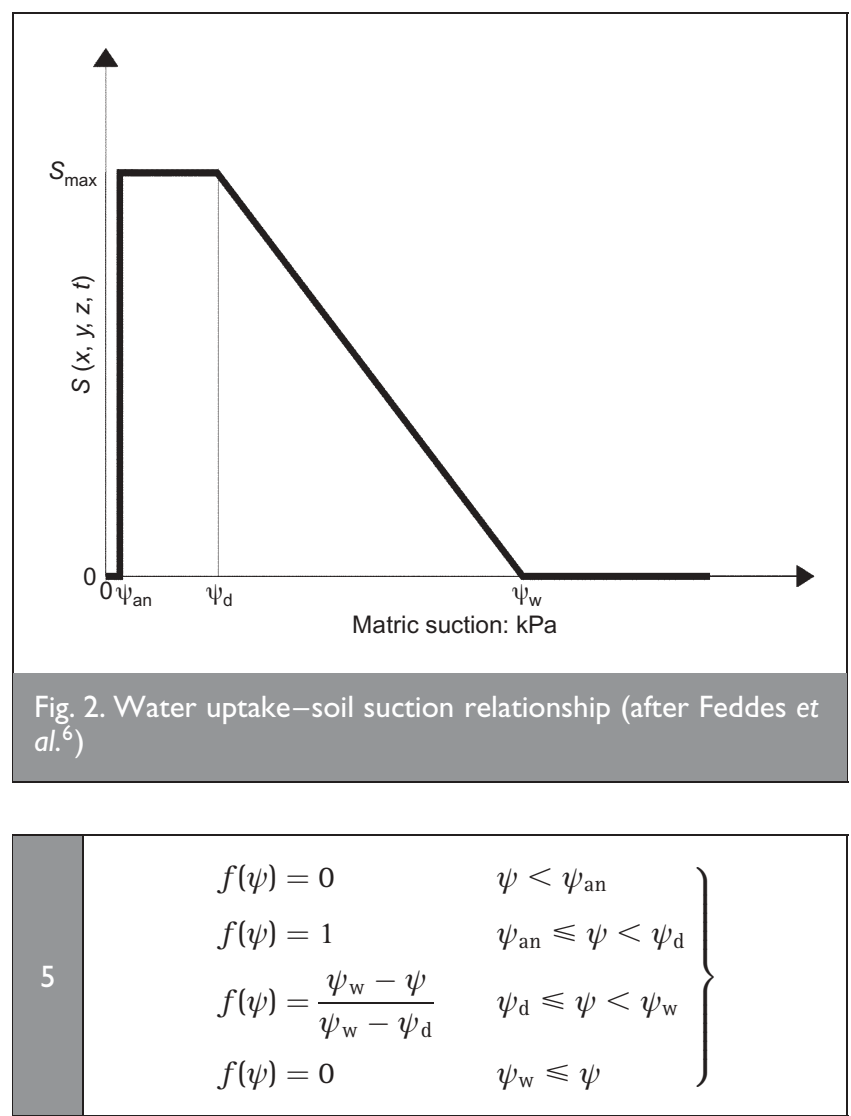

where $\psi_{\mathrm{w}}$ is the soil suction at wilting point, the suction limit at which a particular vegetation is unable to draw moisture from the soil; $\psi_{\mathrm{d}}$ is the highest value of $\psi$; and $\psi_{\text {an }}$ (soil suction at anaerobiosis point) is the lowest value of $\psi$ at $S=$ $S_{\max }$, where $S_{\max }$ is the maximum rate of root water uptake. An experimental study by Kutilek and Nielsen ${ }^{11}$ also confirms the same trend as given by Feddes et al., ${ }^{6}$ as illustrated in Fig. 2.

\subsection{Root distribution}

When access to water is not limited, the distribution of transpiration within the root depends on the root density distribution and the potential transpiration distribution within the root zone. Hence:

\begin{tabular}{|c|c|c|}
\hline Radcliffe et al. ${ }^{4}$ & $f(\theta)=\frac{0.0001}{0.0001+0.9999 \mathrm{e}^{-1.45 \theta}}$ & $\theta=$ volumetric soil moisture content, $f(\theta)=f(\psi)$ \\
\hline Molz ${ }^{8}$ & $f(\psi) G(\beta)=\frac{\theta(z, t) L(z, t)\left[\psi(z, t)-\phi_{x}(t)\right]}{\int_{0}^{v(t)} \theta(z, t) L(z, t)\left[\psi(z, t)-\phi_{x}(t)\right] d z}$ & $\begin{array}{l}\theta(z, t)=\text { volumetric soil water content, } L(z, t)=\text { length of } \\
\text { roots per unit soil volume, } v(t)=\text { depth of root zone, } \phi_{x}(t) \\
=\text { water potential of root xylem, } G(\beta)=\text { root density } \\
\text { distribution function }\end{array}$ \\
\hline Perrochet ${ }^{9}$ & $\begin{array}{ll}f(\psi)=\frac{k(\psi)\left(\psi_{\mathrm{r}}-\psi\right)}{\mathrm{k}\left(\psi_{0}\right)\left(\psi_{\mathrm{r}}-\psi_{0}\right)} & |\psi|>\left|\psi_{0}\right| \\
f(\psi)=\mathrm{I} & |\psi| \leqslant\left|\psi_{0}\right|\end{array}$ & $\begin{array}{l}\mathrm{k}(\psi)=\text { hydraulic conductivity of soil, } \psi=\text { soil suction } \\
\text { around roots, } \psi_{\mathrm{r}}=\text { root suction generated by plant, } \psi_{0}= \\
\text { soil suction around roots from which transpiration rate } \\
\text { starts to diminish }\end{array}$ \\
\hline Novak ${ }^{10}$ & 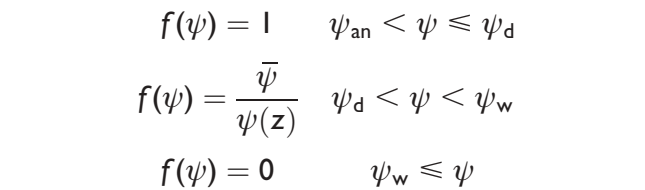 & $\begin{array}{l}\psi_{\mathrm{w}}=\text { soil suction at wilting point, } \psi_{\mathrm{d}}=\text { highest value of } \psi \\
\text { at which } S=S_{\max }, \psi_{\mathrm{an}}=\text { soil suction at anaerobiosis point, } \\
\bar{\psi}=\text { average value of } \psi \text { in depth interval where } \\
\psi_{\mathrm{d}}<\psi<\psi_{\mathrm{w}}\end{array}$ \\
\hline
\end{tabular}


where $G(\beta)$ is a function associated with the root density distribution; $F\left(T_{\mathrm{P}}\right)$ is a function to take the potential transpiration distribution into account; and $\beta(x, y, z, t)$ is the root density. Substituting equation (6) into equation (4) gives

\begin{tabular}{|l|l|}
\hline 7 & $S(x, y, z, t)=f(\psi) G(\beta) F\left(T_{\mathrm{P}}\right)$ \\
\hline
\end{tabular}

A traditional agronomical belief holds that the root area of trees below the ground may be as extensive or less than the average canopy above. Some researchers ${ }^{3,12-14}$ have proposed that the total cross-sectional area of roots, including the depth and distance from the trunk, can be determined as an exponential relationship. It is assumed by symmetry that the maximum root density is on a circle with $r=r_{0}(t)$ at a depth of $z=z_{0}(t)$, and that the root density decreases exponentially from this maximum value in both the vertical and radial directions. Therefore:

8

$$
\beta(r, z, t)=\beta_{\max }(t) \mathrm{e}^{-k_{1}\left|z-z_{0}(t)\right|-k_{2}\left|r-r_{0}(t)\right|}
$$

where $\beta_{\max }(t)$ is the maximum root density at time $t$, and $k_{1}$ and $k_{2}$ are empirical coefficients that depend on the tree root system and type.

For a given transpiration rate, the rate of water uptake from any particular unit volume of wet soil is proportional to $\beta$. As suggested by Landsberg, ${ }^{14}$ this relationship is non-linear. Based on agronomical research, an asymptotic relationship may be assumed for root water uptake, such as the curve shown in Fig. 3. However, there is an uncertainty in this relationship when the roots become widely separated, which can often be the case when the tree roots penetrate deeply into the soil.

As the hyperbolic tangent function represents a non-linear asymptotic curve, the following equation is suggested for the root density correction factor, $G(\beta)$ :

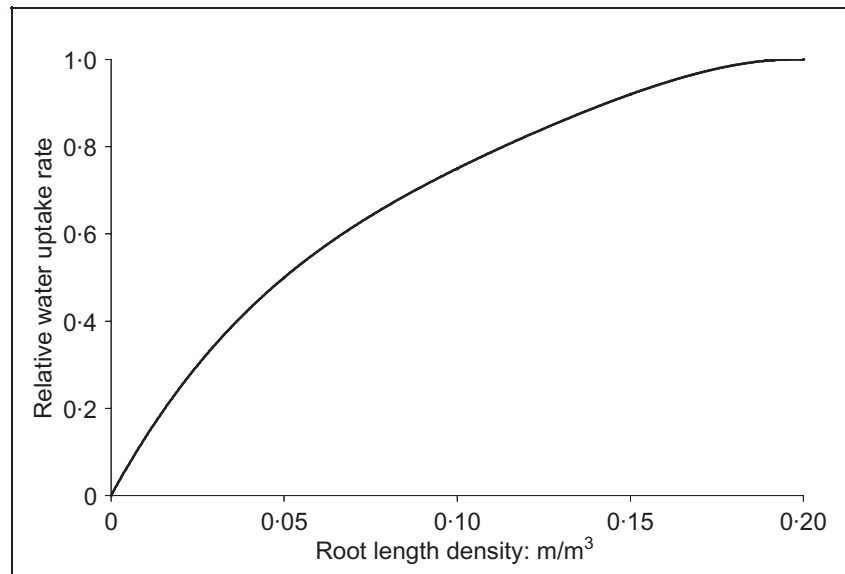

Fig. 3. General relationship between root length density $(\beta)$ and relative water uptake (modified after Landsberg ${ }^{14}$ ) where $k_{3}$ is an empirical coefficient. The denominator is applied to this factor to normalise the function within the root zone, where

$\int_{V(t)} G(\beta) \mathrm{d} V=1$

To define the overall root zone shape where the active and the main roots unite (Fig. 1(c)), it is assumed that $r_{0}=z_{0}=0$ : hence equation (8) can be rewritten as

10

$$
\beta(r, z, t)=\beta_{\max }(t) \mathrm{e}^{-k_{1} z-k_{2} r}
$$

The boundary condition to determine the root zone shape is then given by

\begin{tabular}{|l|l|}
\hline II & $\frac{\beta(r, z, t)_{\text {boundary }}}{\beta_{\max }(t)}=c_{1}=$ constant \\
\hline
\end{tabular}

where

\begin{tabular}{|l|l|}
\hline 12 & $c_{1}=\mathrm{e}^{-k_{1} z-k_{2} r}$ \\
\hline
\end{tabular}

or

$13 \quad \ln c_{1}=-k_{1} Z-k_{2} r$

Assuming $\ln c_{1}=c_{2}$, then

$$
14 \quad c_{2}=-k_{1} z-k_{2} r
$$

Equation (14) is linear and implies that, based on the exponential distribution of roots, the root zone shape is an inverted cone, as shown in Fig. 4 in the $r-z$ plane.

\subsection{Potential transpiration rate}

The potential transpiration is defined as the evaporation of water from the plant tissues to the atmosphere when the soil moisture content is unrestricted. Therefore the maximum possible root water uptake is called the potential transpiration, which relates to meteorological characteristics as well as to the condition and the age of the plant. Direct measurement of potential transpiration is very difficult: hence indirect estimation is usually carried out in practice. Thus:

$$
\text { I5 } \quad T_{\mathrm{P}}=E T_{\mathrm{P}}-E_{\mathrm{P}}
$$

where $T_{\mathrm{P}}$ is the potential transpiration, $E T_{\mathrm{P}}$ is the potential 


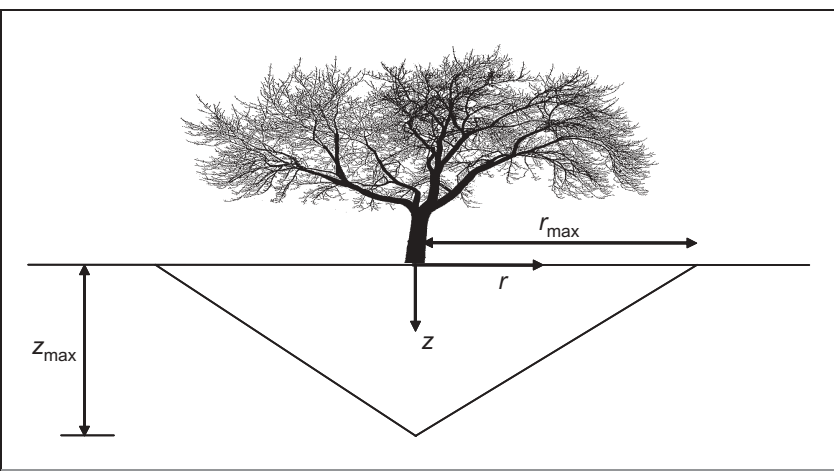

Fig. 4. Proposed root zone shape

evapotranspiration (from both plant and soil), and $E_{\mathrm{P}}$ is the potential evaporation (from the soil surface only).

To estimate $E T_{\mathrm{P}}$ and $E_{\mathrm{P}}$, a combination of energy balance and mass balance methods can be used. Penman, ${ }^{15}$ Monteith ${ }^{16}$ and Rijtema ${ }^{17}$ developed appropriate methods for determining the potential transpiration through potential evapotranspiration and evaporation. For example, potential transpiration based on Penman-Brutsaert's model, further described by Lai and Katual, ${ }^{18}$ is given by

$$
T_{\mathrm{P}}=W\left(R_{\mathrm{n}}-G\right)+(1-W) E_{\mathrm{A}}
$$

where $T_{\mathrm{P}}$ is the potential latent heat flux; $R_{\mathrm{n}}$ is the net radiation; $G$ is the soil heat flux; $W$ is a dimensionless weighted function that depends on the slope of the saturation vapour pressure-temperature curve and the psychometric constant; and $E_{\mathrm{A}}$ is the atmospheric drying power function.

Referring to the model proposed by Nimah and Hanks, ${ }^{19}$ it can be inferred that the potential transpiration is not distributed uniformly within the root zone, and that a linear distribution with depth for potential transpiration is a more appropriate distribution. Accordingly, the following equation is suggested to take the effect of potential transpiration into account:

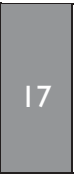

$$
F\left(T_{\mathrm{P}}\right)=\frac{T_{\mathrm{P}}\left(1+k_{4} Z_{\max }-k_{4} z\right)}{\int_{V(t)} G(\beta)\left(1+k_{4} Z_{\max }-k_{4} z\right) \mathrm{d} V}
$$

where $G(\beta)$ is given by equation (9), and $k_{4}$ is an empirical coefficient to take into account the effect of depth on the transpiration rate. The denominator of equation (17) is applied to satisfy the potential transpiration mass balance.

As a result, according to equation (7), the rate of root water uptake, $S(x, y, z)$, can be estimated by multiplying three functions that represent the soil suction effect: $f(\psi)$; the root density effect, $G(\beta)$; and the potential transpiration effect, $F\left(T_{\mathrm{P}}\right)$. To calculate $f(\psi)$, equation (5) suggested by Feddes et $a l .{ }^{6}$ to determine the effects of soil suction is used in this study. In order to determine $G(\beta)$, equation (9) is employed, and to estimate $F\left(T_{\mathrm{P}}\right)$, equation (17) in conjunction with equation (16) is adopted. By substituting equation (7) in equation (2) and solving the differential equation, water movement within unsaturated soil caused by transpiration can be quantified.

\section{NUMERICAL IMPLEMENTATION}

Since Richards ${ }^{20}$ presented his theory for flow in unsaturated soils, various aspects of transitory water distribution in porous media have been widely investigated. During the past few decades, governing equations describing water flow in partially saturated soil have also been developed comprehensively. These equations are mainly non-linear partial differential equations where some simplifications can lead to meaningful closed-form solutions, given distinct boundary and initial conditions. As a fluid passes through a porous medium, a coupled flow-deformation analysis is required to capture the interaction among the soil, air and water phases. The governing equations for pore fluid diffusion-deformation are a combination of equation (2) and the relevant elasto-plastic deformation equations.

The basic effective stress theory adopted in this study to analyse unsaturated soil behaviour is inspired after Bishop: ${ }^{21}$

$$
\sigma_{i j}^{\prime}=\sigma_{\mathrm{ij}}-u_{\mathrm{a}} \delta_{i j}+\chi\left(u_{\mathrm{a}}-u_{\mathrm{w}}\right) \delta_{i j}
$$

where $\sigma_{i j}^{\prime}$ is the effective stress of a point on a solid skeleton; $\sigma_{i j}$ is the total stress in the porous medium at the point; $u_{\mathrm{a}}$ is the pore air pressure; $u_{\mathrm{w}}$ is the pore water pressure; $\delta_{i j}$ is Kronecker's delta $(=1$ when $i=j$ and 0 when $i \neq j$ ); and $\chi$ is the effective stress parameter, attaining a value of unity for saturated soils and zero for dry soils. In unsaturated soil mechanics the term $\left(u_{\mathrm{a}}-u_{\mathrm{w}}\right)$ is usually called matric suction. The validity of Bishop's effective stress concept for predictions of shear strength and volume change in unsaturated soils has recently been confirmed by Khalili et al. ${ }^{22}$ and Lu and Griffiths. ${ }^{23}$ As mentioned by Bishop, ${ }^{21}$ the value of $\chi$ is related to the degree of saturation and soil structure. Khabbaz ${ }^{24}$ presented a relationship for $\chi$ as a function of matric suction and the air entry value. The degree of saturation is associated with matric suction through the soil water characteristic curve (SWCC). The air entry value, related to the soil structure, can be determined using the SWCC.

The non-linear finite element program ABAQUS was employed to investigate soil suction development induced by tree transpiration. ABAQUS is a general-purpose finite element program for analysing engineering problems, with the capability of coupled pore fluid-stress analysis for partially saturated soil. ${ }^{25}$ In this study, ABAQUS code using the effective stress-based equations has been employed for the numerical analysis. The results of the ABAQUS program were first evaluated against the results for the soil suction profile in the vicinity of a row of trees presented by Fredlund and Hung. ${ }^{26}$ They applied the theory of stress state variables for unsaturated soils, and analysed the problem with a differential equation solver, PDEeas2D.

In order to verify the proposed mathematical model for root water uptake rate, two case histories have been considered. In the first case, the soil suction development in the vicinity of a spotted gum tree has been simulated. Then the ABAQUS predictions have been compared with the measured field data 
reported by Jaksa et al. ${ }^{27}$ The second case history is associated with the results of the field moisture content measured in the vicinity of a single lime tree reported by Biddle. ${ }^{28}$ In both case studies reasonable assumptions have been made for a number of required parameters of the model that were not available in the reported data. The key parameters required to be measured or estimated accurately for predicting the behaviour of expansive clays in the vicinity of vegetation are potential transpiration $\left(T_{\mathrm{P}}\right)$, saturated permeability $\left(k_{\mathrm{S}}\right)$ and wilting point suction $\left(\psi_{\mathrm{w}}\right)$. Moreover, the other parameters including the relevant soil properties and root zone characteristics should be measured accurately either in the laboratory or in the field.

\section{I. Initial evaluation of numerical model}

The initial evaluation exercise deals with the deformation and soil suction profile near a line of trees using a two-dimensional finite element mesh (Fig. 5), based on ABAQUS code. The mesh consists of 4-noded linear strain quadrilateral elements (CPE4P) with four displacement and four pore pressure nodes positioned at the corners of each element. The entire FE mesh consists of 13041 nodes and 12800 elements. As the model parameters should be exactly the same as those used by Fredlund and Hung $^{26}$ for the purpose of comparison, the coefficient of soil permeability $(k)$ is described by equation (19) with a saturated coefficient of permeability $\left(k_{\mathrm{s}}\right)$ equal to $5 \cdot 79 \times 10^{-8} \mathrm{~m} / \mathrm{s}$, and the parameters $a$ and $n$ are taken to be $0 \cdot 001$ and 2 respectively. ${ }^{29}$

$$
k=\frac{k_{\mathrm{s}}}{1+a\left(\psi / \rho_{\mathrm{w}} g\right)^{n}}
$$

Based on typical field measurements, the initial void ratio of the soil was assumed to be unity. In the same way as Fredlund and Hung, ${ }^{26}$ the initial matric suction was estimated on the basis of a constant water table at $15 \mathrm{~m}$ depth. The discharge of water through the tree roots decreased from $15 \mathrm{~mm} /$ day at $1 \mathrm{~m}$ depth, to $0 \mathrm{~mm} /$ day at $3 \mathrm{~m}$ depth following a linear relationship. The soil water characteristic curve employed in this study is shown in Fig. 6.

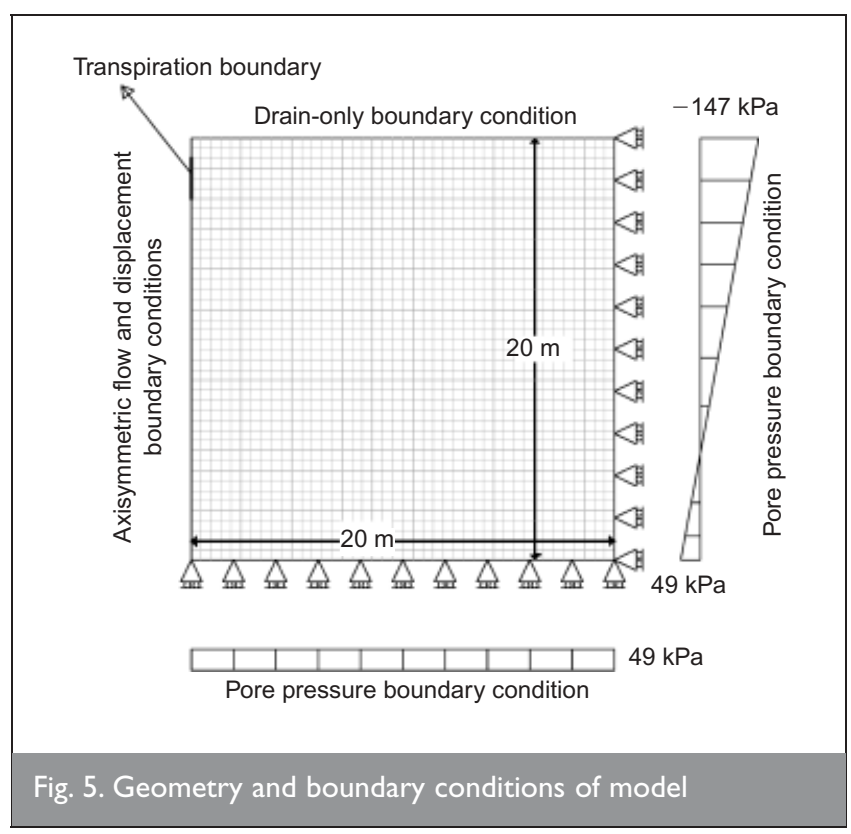

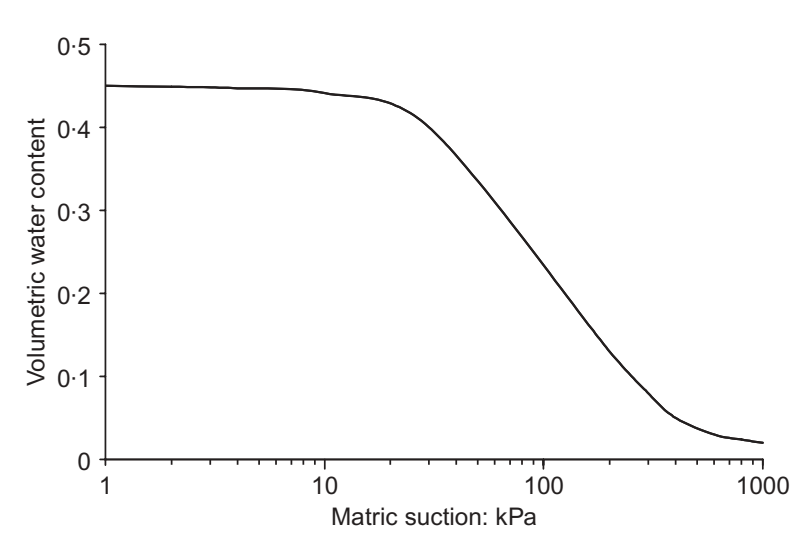

Fig. 6. Soil water characteristic curve (after Fredlund and Hung ${ }^{26}$ )

The type of soil is normally consolidated clay, and its consolidation behaviour can be defined by

\begin{tabular}{|l|l|}
\hline 20 & $\mathrm{~d} e^{\mathrm{el}}=C_{\mathrm{c}} \ln \left(\frac{p_{0}+\mathrm{d} p}{\mathrm{~d} p}\right)$ \\
\hline
\end{tabular}

where de denotes the change of void ratio in the element; $C_{\mathrm{c}}$ is the compression index; $p_{0}$ is the initial mean effective stress; and $\mathrm{d} p$ is the mean effective stress change on the soil skeleton. For overconsolidated clays $C_{\mathrm{c}}$ is replaced by the swelling index, $C_{\mathrm{s}}$. In the current analysis, the authors have employed the general theory of effective stress for unsaturated soil (originally conceptualised by Bishop ${ }^{21}$ ) that is implemented in the ABAQUS source code, rather than the distinctly different stress state variables employed by Fredlund and Hung. ${ }^{26}$ Based on settlement data, an equivalent compression index of $0 \cdot 15$ and a Poisson's ratio of $0 \cdot 30$ have been assumed for the ABAQUS analysis in lieu of Fredlund and Hung's ${ }^{26}$ coefficients.

Figures 7 to 9 indicate the contours of the initial matric suction after 1 month, 6 months and 1 year, respectively, based on the FE analysis. Fig. 10 shows a comparison between the results of the equilibrium matric suction obtained from Fredlund and Hung analysis ${ }^{26}$ and the current model, and Fig. 11 shows a comparison of the vertical settlement results. As Figs 10 and 11 indicate, the numerical results are in acceptable agreement with Fredlund and Hung's analysis. ${ }^{26}$ The main reason for the notable disparity of the predicted results is the two distinctly different unsaturated soil models utilised in the current study (Bishop's effective stress theory for unsaturated soils in ABAQUS, and that of Fredlund and Hung, i.e. stress state variables for unsaturated soil). As these two theories influence the soil volume change in different ways, the disparities are more evident in the settlement contours than in the suction profiles (Figs 10 and 11). This initial evaluation exercise confirms that if the relevant parameters are known, the current finite element model is appropriate to predict the generated matric suction and the associated deformation caused by tree transpiration.

\subsection{Verification of proposed root water uptake model}

3.2.1. Case study 1. This case history is associated with the results of field suction, measured in the vicinity of a single 


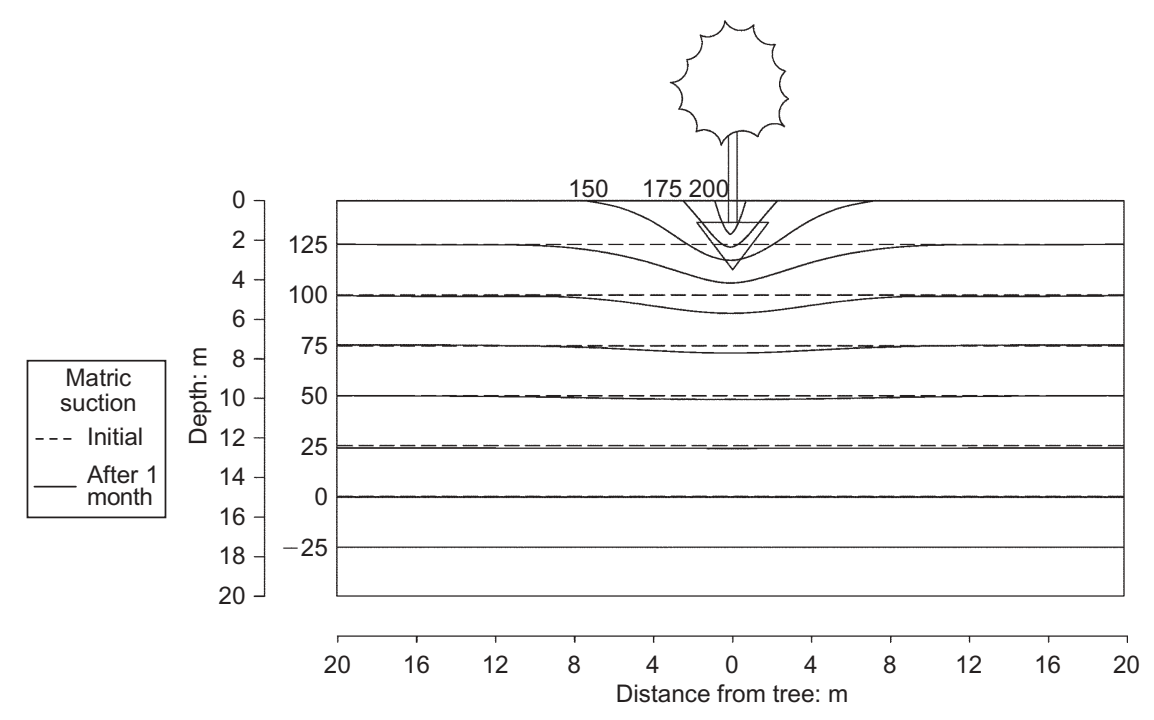

Fig. 7. Initial matric suction $(\mathrm{kPa})$ and matric suction $(\mathrm{kPa})$ profile after I month

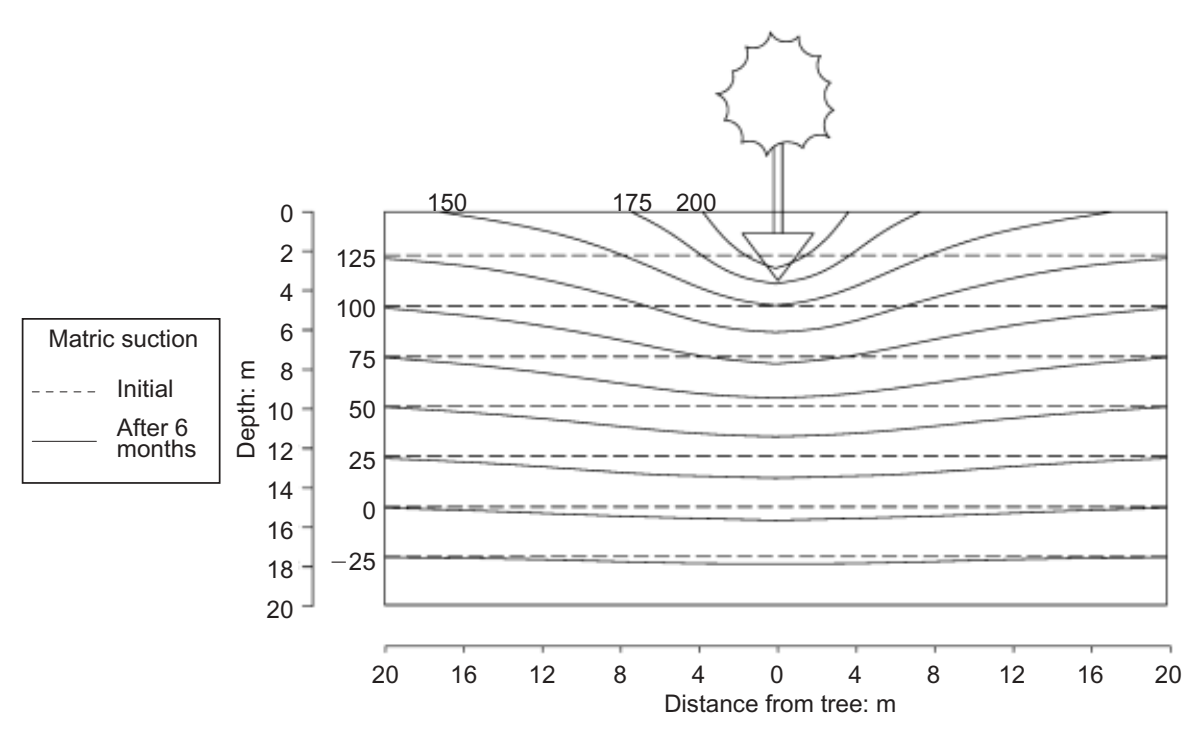

Fig. 8. Initial matric suction $(\mathrm{kPa})$ and matric suction $(\mathrm{kPa})$ profle after 6 months

$20 \mathrm{~m}$ high gum tree (Eucalyptus maculata) in Adelaide, South Australia, reported by Jaksa et al. ${ }^{27}$ The tree is located in a relatively flat, open and grassed reserve of clay soil. Table 2 shows the estimated parameters used in the finite element analysis, based on available literature. Seasonal effects have been simplified by considering the average annual potential transpiration rate. As reported by Jaksa et al.,${ }^{27}$ four boreholes, $40 \mathrm{~mm}$ in diameter, were drilled to a depth of $4 \mathrm{~m}$ along a line at radial distances of $2 \cdot 2,5,10$ and $20 \mathrm{~m}$ from the tree trunk. The field study was conducted in November 2000. Total soil suction measurements were taken in the laboratory on cored samples using a transistor psychrometer.

The numerical analysis in this case, similar to the evaluation exercise, is based on the effective stress theory of unsaturated soils incorporated in ABAQUS. The authors' theoretical model representing the rate of root water uptake distribution within the root zone was included in the FE analysis through appropriate Visual Fortran subroutines. The main subroutine includes the rate of root water uptake as moisture flux boundary, applied along the top side of all elements within the root zone. In other words, equation (7) incorporating equations (5), (8), (9) and (17) has been implemented in the numerical model as boundary flux, which can determine the rate of root water uptake within the root zone at each time increment. In this study it is assumed that the tree is well developed, and that the dimensions have not changed during the time interval considered in the analysis. A two-dimensional plane strain finite element mesh with 4-node bilinear displacement and pore pressure elements (CPE4P) was used to model the development of soil suction. The overall mesh consists of 6561 nodes and 6400 elements, and the geometry and boundary conditions of the model are schematically illustrated in Fig. 12. As the geometry of the proposed mesh is considered sufficiently large, there may be marginal implications associated with the elements located at the far sides of the mesh. Because of symmetry, a zero flux boundary was applied along the left boundary of the mesh. It is assumed that rainfall 


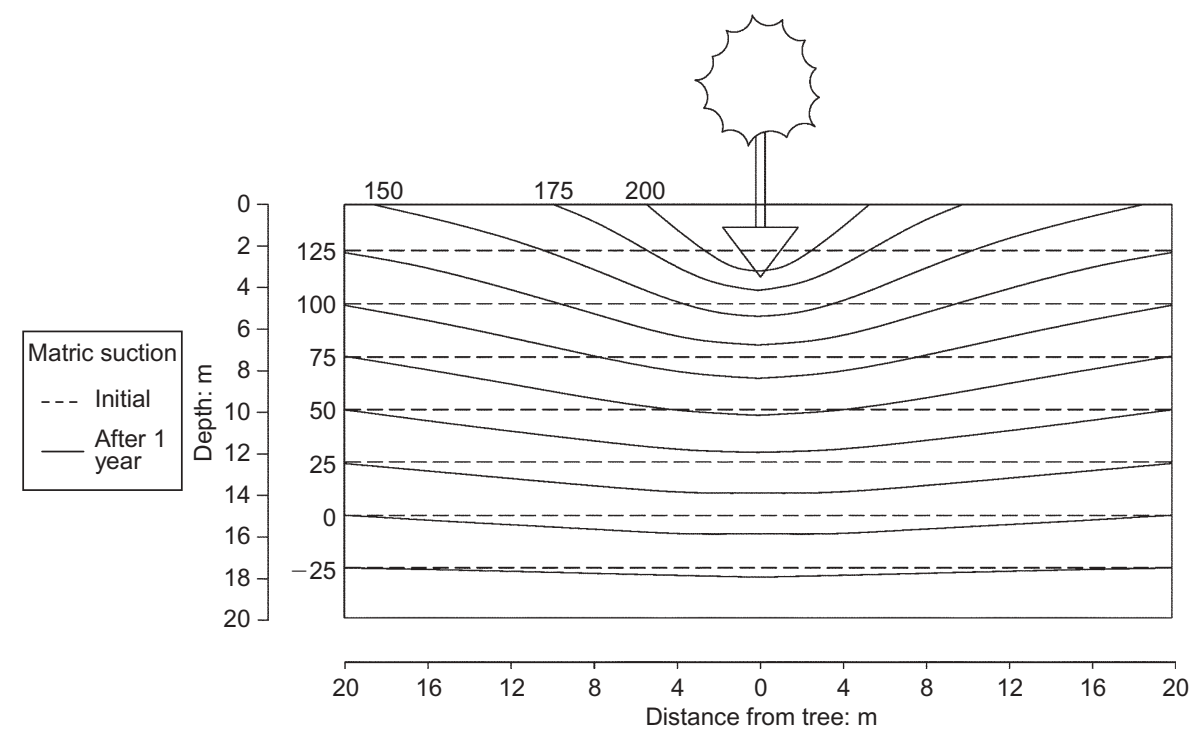

Fig. 9. Initial matric suction $(\mathrm{kPa})$ and matric suction $(\mathrm{kPa})$ profile after I year

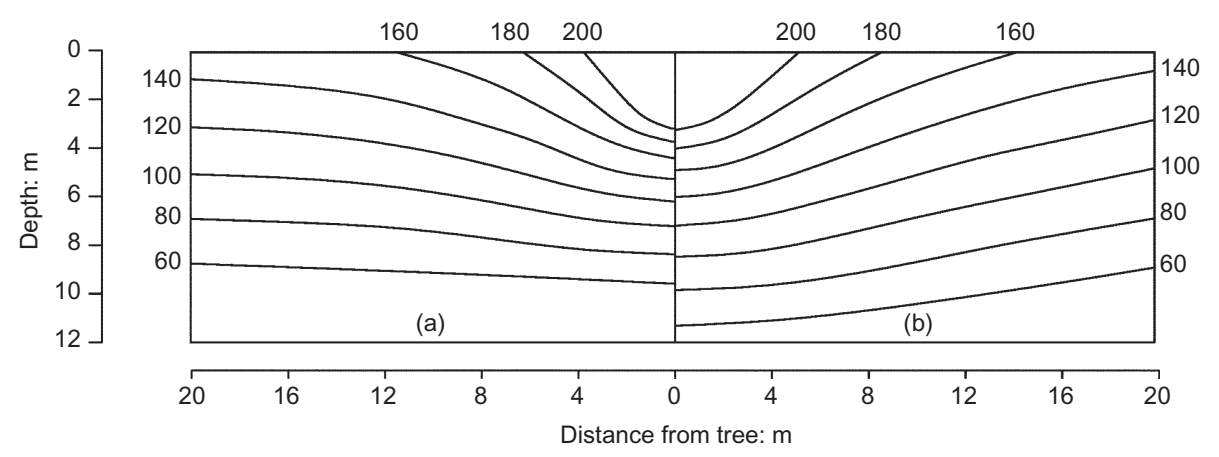

Fig. 10. Contours of soil matric suction ( $\mathrm{kPa}$ ) in vicinity of a row of trees: (a) Fredlund and Hung, ${ }^{26}$ (b) current finite element analysis

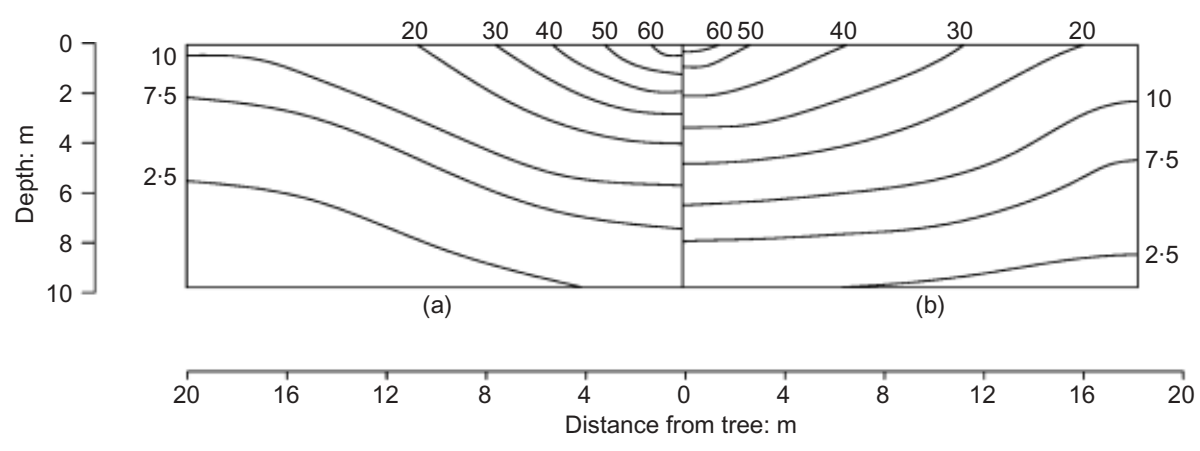

Fig. I I. Contours of vertical displacement $(\mathrm{mm})$ in vicinity of a row of trees: (a) Fredlund and Hung; ${ }^{26}$ (b) current finite element analysis

and evaporation can balance each other: thus a "no water inflow' condition is applied on the top of the soil surface.

The finite element analysis was conducted in two stages:

(a) Geostatic: for checking and modifying the defined initial conditions for the steady-state equilibrium of ground under geostatic loading. This stage is used to ensure that the analysis begins from a state of equilibrium under geostatic loading.

(b) Consolidation: for transient response analysis of partially saturated soil under transpiration. To avoid non-physical 


\begin{tabular}{|llll|}
\hline Parameter & Value & Reference & Comments \\
\hline$\psi_{\text {an }}$ & $4.9 \mathrm{kPa}$ & Feddes et al. & \\
$\psi_{\mathrm{d}}$ & $40 \mathrm{kPa}$ & Feddes et al. $^{5,6}$ & Clayey soil with air content of 0.04 \\
$k_{1}$ & 1.5 & Knight $^{30}$ & $40<\psi_{\mathrm{d}}<80 \mathrm{kPa}$ \\
$k_{2}$ & 2.0 & Knight $^{30}$ & Root shape coefficient associated with vertical coordinate \\
$T_{\mathrm{P}}$ & $9 \mathrm{~mm} /$ day & Dunin et al. & Root shape coefficient associated with radial coordinate \\
& & Regularly watered condition \\
Table 2. Parameters applied in finite element analysis of case study I
\end{tabular}
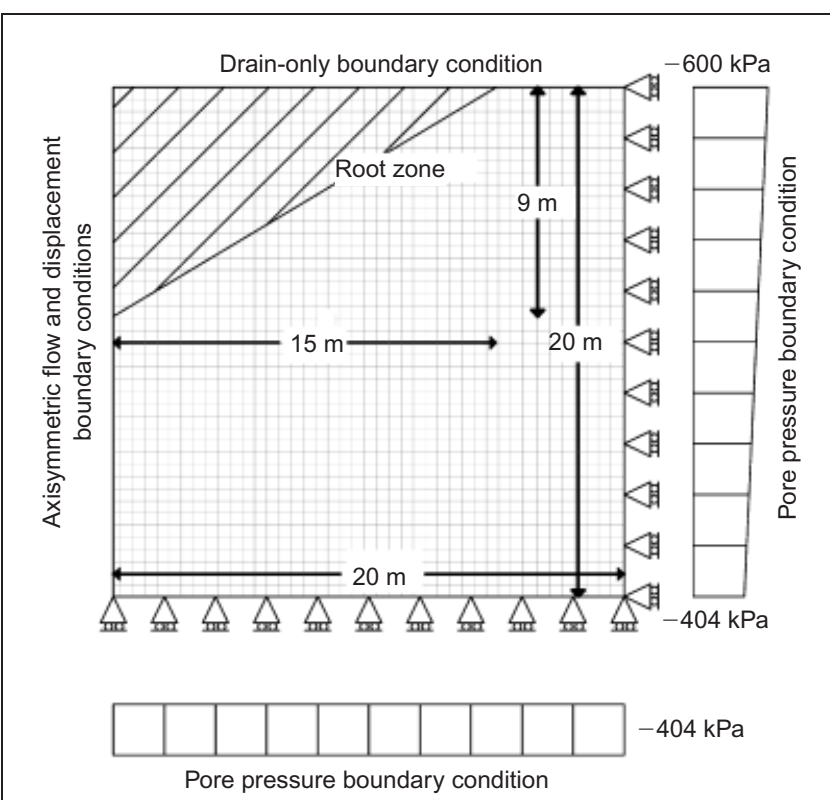

Fig. 12. Geometry and boundary conditions of case history I

oscillations and also convergence problems caused by nonlinearities, this stage included a time-dependent analysis using 1-day intervals for a 1-year period with continuous root water uptake.

The coefficient of unsaturated soil permeability has been calculated based on the following equation with a saturated coefficient of permeability, $k_{\mathrm{s}}=5 \times 10^{-9} \mathrm{~m} / \mathrm{s}$ :

$$
2 \text { I } \quad k=k_{\mathrm{s}} \times S_{\mathrm{r}}^{3}
$$

where $S_{\mathrm{r}}$ is the degree of saturation.

The soil water characteristic curve used in this analysis is based on a relationship suggested by Zapata et al. ${ }^{32}$ A family of curves for different $w \times \mathrm{PI}$ is shown in Fig. 13, where $w$ is the fraction of soil passing sieve \#200 (75 $\mu \mathrm{m})$ as an index between 0 to 1 , and PI is the plasticity index.

The soil is assumed to be an overconsolidated clay, given the applied stress range. In addition to the material properties and parameters given earlier in Table 2, the other assumed

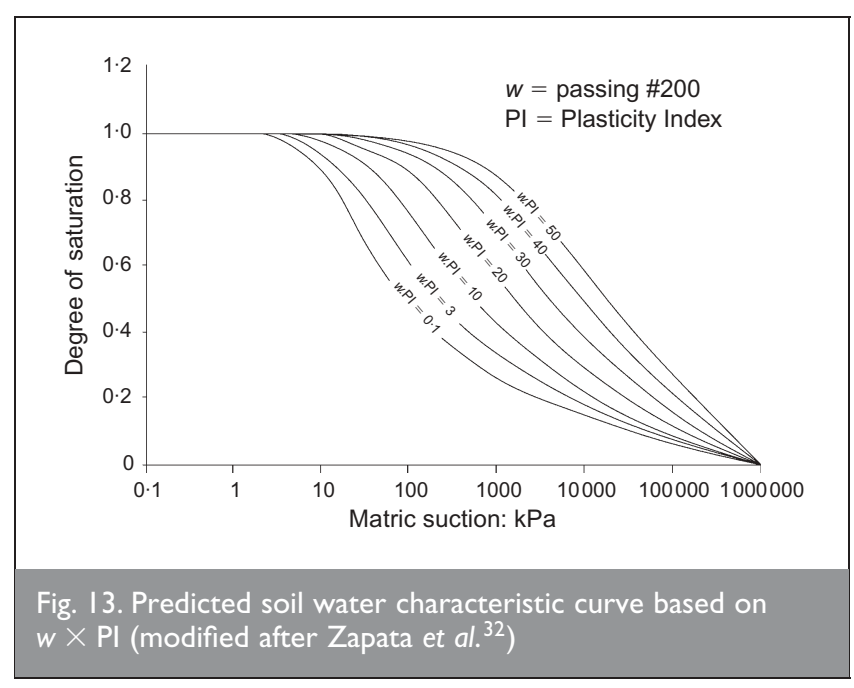

\begin{tabular}{|c|c|c|}
\hline Parameter & Value & Comments \\
\hline$r_{0}$ & $7 \mathrm{~m}$ & Radial coordinate of maximum root density point \\
\hline $\mathrm{z}_{0}$ & $3 \mathrm{~m}$ & Vertical coordinate of maximum root density point \\
\hline$\beta_{\max }(t)$ & $25 \mathrm{~m}^{-2}$ & Maximum root length density ${ }^{30}$ \\
\hline$k_{3}$ & $8.74 \times 10^{-2} \mathrm{~m}^{-1}$ & Taken from general shape of root suggested by Landsberg ${ }^{14}$ \\
\hline$k_{4}$ & 0 & $\begin{array}{l}\text { In this case, it is assumed that potential transpiration is distributed } \\
\text { uniformly }\end{array}$ \\
\hline$r_{\max }$ & $15 \mathrm{~m}$ & Estimated from field data ${ }^{27}\left(10<r_{\max }<20\right)$ \\
\hline$z_{\max }$ & $9 \mathrm{~m}$ & Estimated from field data ${ }^{27}$ \\
\hline$\gamma_{d}$ & $18.6 \mathrm{kN} / \mathrm{m}^{3}$ & Typical expansive earth soil in Adelaide, Australia \\
\hline$C_{s}$ & 0.05 & Average value for clayey soils in vicinity of building foundations \\
\hline$v$ & 0.30 & Typical value for clayey soils \\
\hline & $5 \times 10^{-9} \mathrm{~m} / \mathrm{s}$ & Typical value for clayey soils in vicinity of building foundations \\
\hline$w \times P I=$ passing $\# 200 \times$ plasticity index & 50 & High-plasticity clayey soil \\
\hline$\psi_{\mathrm{w}}$ & $3000 \mathrm{kPa}$ & $\begin{array}{l}\text { Estimated from field measurements }{ }^{27,33}\left(1550 \mathrm{kPa} \leqslant \psi_{\mathrm{w}} \leqslant\right. \\
3100 \mathrm{kPa})\end{array}$ \\
\hline Initial void ratio, $e_{0}$ & 1 & Typical clay soil \\
\hline
\end{tabular}


parameters used in the finite element analysis are specified in Table 3. According to the field measurements of soil suction measured by Jaksa et al., ${ }^{27}$ the initial matric suction is assumed to be hydrostatic. as shown in Fig. 14. Owing to high matric suction within the soil close to the surface, the depth of the tree roots is considerably greater than that considered in the previous analysis. $^{26}$

The predicted steady-state soil matric suction based on the finite element analysis is presented in Fig. 15, and the measured values reported by Jaksa et al. ${ }^{27}$ are plotted in Fig. 16 for four different depths. As shown in Fig. 15, in comparison with the suction profile presented by Fredlund and Hung (Fig. 10), the numerical analysis (capturing the root water uptake variation in the soil matrix) indicates that the maximum suction change occurs at a point away from the tree trunk. It can be noted that the maximum suction change takes place at the location of the maximum root density, as computed by the model. Comparison between Figs 15 and 16 indicates that the maximum root density occurs at the point $\left(r_{0}, z_{0}\right)=(7 \mathrm{~m}, 3 \mathrm{~m})$. As direct measurements are not available for points at which $r$ $=7 \mathrm{~m}$, the interpolated (estimated) field values are plotted in Fig. 16 with dashed lines. In this case, the interpolated value for the radial distance at which the maximum suction change occurs (i.e. $r=7 \mathrm{~m}$ ) is in accordance with Jaksa et al., ${ }^{27}$ who pointed out that the maximum suction change would occur at a radial distance of 5-10 m from the tree trunk. Comparison between the field data (Fig. 16) and numerical predictions (Fig. 15) shows that underneath the tree trunk smaller suction values are observed compared with the predictions. One possible reason for this could be related to irrigation around the tree trunk or the collection of rainwater beside the trunk, resulting in significant reduction of suction. Field measurements also indicate that the soil suction varies considerably with depth, whereas the numerical results indicate less sensitivity to depth. It is of relevance to note that, in the numerical analysis, a homogeneous soil profile has been assumed in Fig. 15. In contrast, a heterogeneous soil profile can influence the root

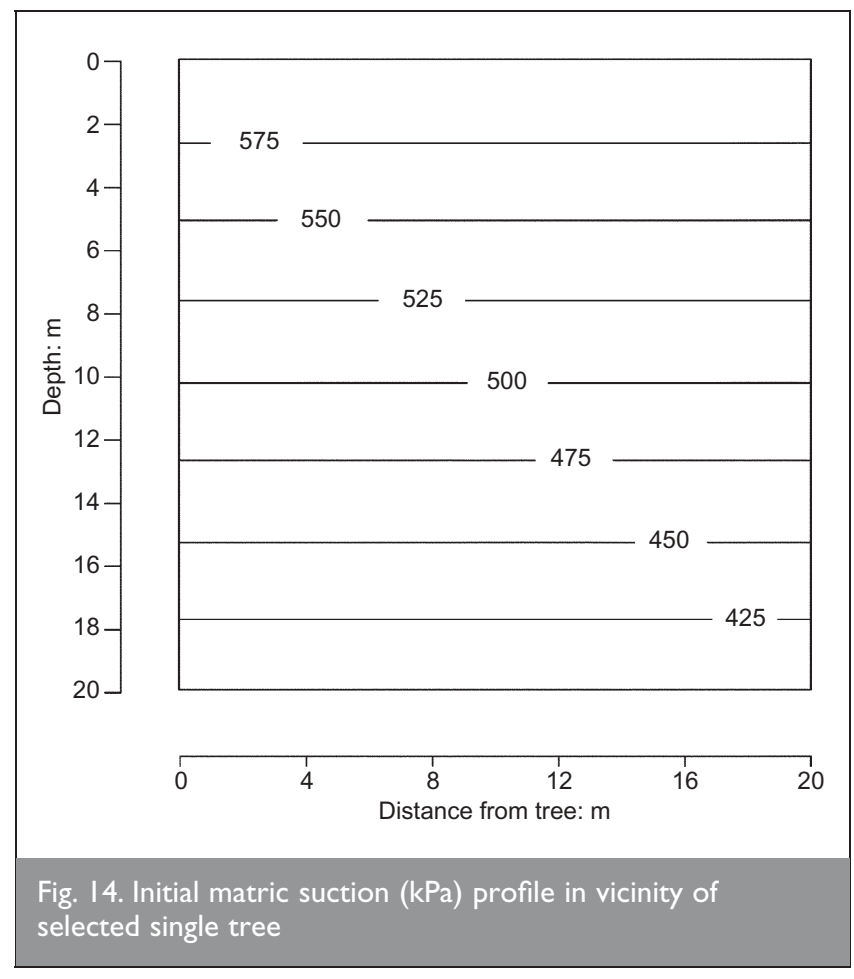

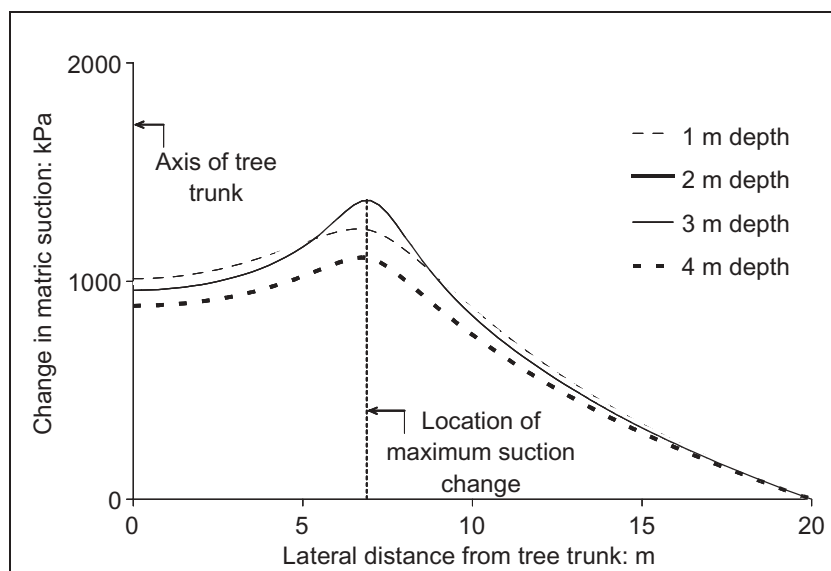

Fig. I5. Numerical prediction of matric suction change against lateral distance from tree trunk after I year of continuous transpiration

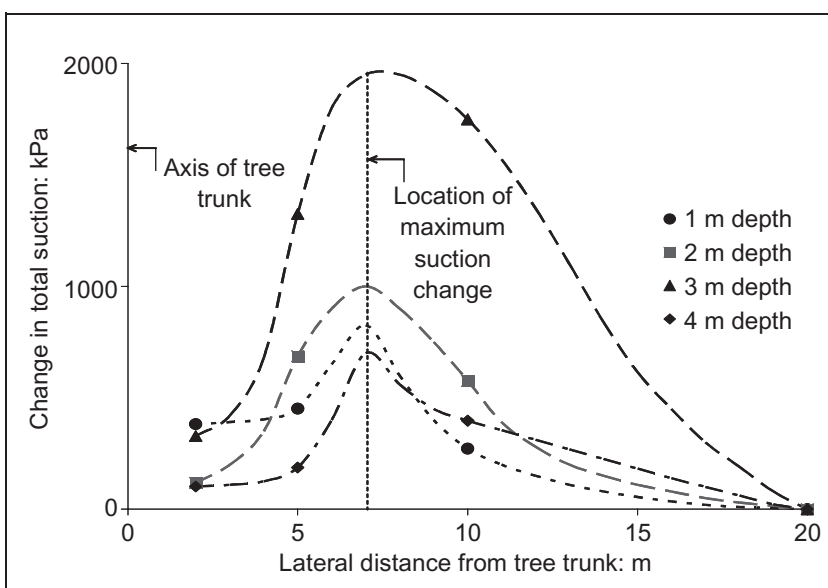

Fig. 16. Field measurements of total suction changes against lateral distance from tree trunk (after Jaksa et al. ${ }^{27}$ )

distribution, thereby affecting the suction distribution significantly. In Fig. 15, as the soil is assumed to be homogeneous, the effect of depth seems to be relatively insignificant, whereas in Fig. 16 the actual field data are probably influenced by the soil heterogeneity, which is reflected by the depth sensitivity of the measured suction.

Figures 17 and 18 depict the ground settlement at various depths for this case study after 1 month and 1 year respectively. In this study only the suction-related settlement is considered. The results show that, after 1 year of continuous transpiration, the rate of change in matric suction $(\mathrm{d} \psi / \mathrm{d} t)$ is less than $10^{-6} \mathrm{kPa} / \mathrm{s}$, which is considered as the steady-state (equilibrium) condition. It can be seen that the movements near the ground surface would be considerable after 1 year within a radial distance of about $20 \mathrm{~m}$ around the tree trunk. As shown in Fig. 17, the maximum ground settlement after 1 month occurs near the point $\left(r_{0}, 0\right)$ (i.e. on the surface, when $\left.r=r_{0}=7 \mathrm{~m}\right)$.

Figure 18 indicates that the maximum ground settlement under steady-state conditions takes place below the tree trunk after 1 year. A single tree can influence the ground for a significant distance. For example, if the maximum allowable foundation 


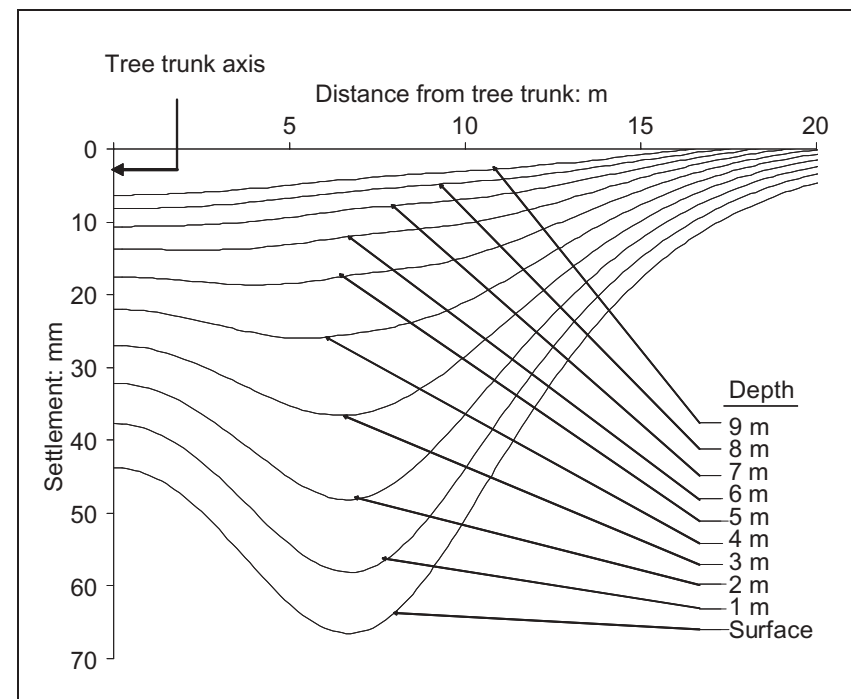

Fig. 17. Ground settlement at various depths after I month

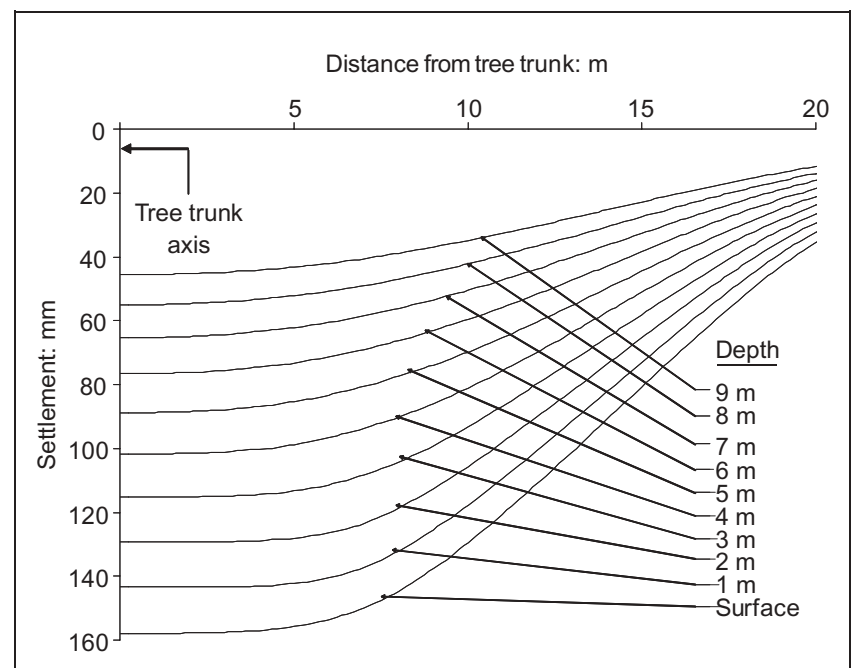

Fig. 18. Ground settlement at various depths after 12 months

settlement is assumed to be $25 \mathrm{~mm}$, then the selected single tree can influence the foundation within a distance of $20 \mathrm{~m}$. The ground settlement would decrease rapidly with radial distance up to $20 \mathrm{~m}$. Comparison between Figs 17 and 18 shows that the radius of the influence zone (in which the ground settlement is greater than $25 \mathrm{~mm}$ ) increases from about $15 \mathrm{~m}$ at the first month to more than $20 \mathrm{~m}$ after 1 year. Furthermore, because of the axisymmetric boundary flow under the trunk (left side of the mesh in Fig. 12), the point of the maximum settlement moves toward the tree axis. The predicted displacements, shown in Fig. 18, have the same pattern of settlement as those monitored by Bozozuk and Burn. ${ }^{34}$ On the ground surface, the $158 \mathrm{~mm}$ vertical settlement at the tree trunk location decreases to about $40 \mathrm{~mm}$ at $20 \mathrm{~m}$ away from the tree trunk (Fig. 18). In addition, comparison between Figs 17 and 18 indicates that the rate of settlement in the first month after starting the transpiration is much faster than the corresponding rate after 1 year, as expected. For instance, on the ground surface at the tree trunk location, the value of settlement of $43 \mathrm{~mm}$ in the first month gradually increased to $158 \mathrm{~mm}$ after 12 months.

3.2.2. Case study 2. The second case history is related to the results of the field moisture content measured in the vicinity of a single $14 \mathrm{~m}$ high lime tree in Milton Keynes, UK, reported by Biddle. ${ }^{28}$ The tree is located in a mown grass area of Boulder clay. Table 4 shows the estimated parameters used in the finite element analysis, based on the available data in the literature. As reported by Biddle, ${ }^{28}$ a soil moisture probe incorporating a $70 \mathrm{mCi}$ americium-241/beryllium source was used to measure the moisture content. Also, five access tubes were inserted at varying distances, wherever possible along a single radius. The distances from the tree were $1.4 \mathrm{~m}, 2.8 \mathrm{~m}, 5.6 \mathrm{~m}$ and $11.2 \mathrm{~m}$. A comparison access tube was located at a distance of twice the tree height $(28 \mathrm{~m})$, which is assumed to be unaffected by the tree root suction.

The geometry and boundary conditions of the finite element model are schematically illustrated in Fig. 19. Flow and displacement conditions around the soil mesh are similar to those in case study 1 . The overall mesh consists of 1326 nodes and 1250 elements. A finite element analysis similar to case study 1 was conducted in two stages: geostatic and consolidation. The root water uptake model was implemented in the numerical scheme via a Visual Fortran subroutine similar to case study 1 . The soil water characteristic curve shown in Fig. 13 was employed in the analysis of this case study also. The osmotic suction effect was assumed to be negligible. The material properties and the main parameters used in this analysis have been given earlier in Table 4; the other required parameters are presented in Table 5.

The predicted steady-state soil matric suction profiles at depths of $0.5,1$ and $1.5 \mathrm{~m}$ below the ground surface based on the finite element analysis are shown in Fig. 20. The maximum change in the soil matric suction occurs at $0.5 \mathrm{~m}$ depth, which is also the location of the maximum root density (i.e. $z=z_{0}=$ $0.5 \mathrm{~m}$ ). The predicted soil suction changes as shown in Fig. 20

\begin{tabular}{|c|c|c|c|}
\hline Parameter & Value & Reference & Comments \\
\hline$\psi_{\mathrm{an}}$ & $4.9 \mathrm{kPa}$ & Feddes et $a .^{5}$ & Clay soil with air content of 0.04 \\
\hline$\psi_{\mathrm{w}}$ & $\mathrm{I} 500 \mathrm{kPa}$ & Feddes et al..$^{5}$ & $1500 \leqslant \psi_{\mathrm{w}} \leqslant 2000 \mathrm{kPa}$ \\
\hline$\psi_{\mathrm{d}}$ & $40 \mathrm{kPa}$ & Feddes et al. ${ }^{6}$ & $40<\psi_{\mathrm{d}}<80 \mathrm{kPa}$ \\
\hline$\gamma$ & $21 \mathrm{kN} / \mathrm{m}^{3}$ & Powrie et al. ${ }^{35}$ & Typical value for Boulder clay \\
\hline$k_{\mathrm{s}}$ & $10^{-10} \mathrm{~m} / \mathrm{s}$ & Lehane and Simpson ${ }^{36}$ & Typical value for Boulder clay \\
\hline PI & 23 & Biddle $^{28}$ & Measured \\
\hline$e_{0}$ & 0.60 & Powrie et al. ${ }^{35}$ & Typical value for Boulder clay \\
\hline$C_{c}$ & 0.13 & Skempton ${ }^{37}$ & Typical value for Boulder clay \\
\hline
\end{tabular}



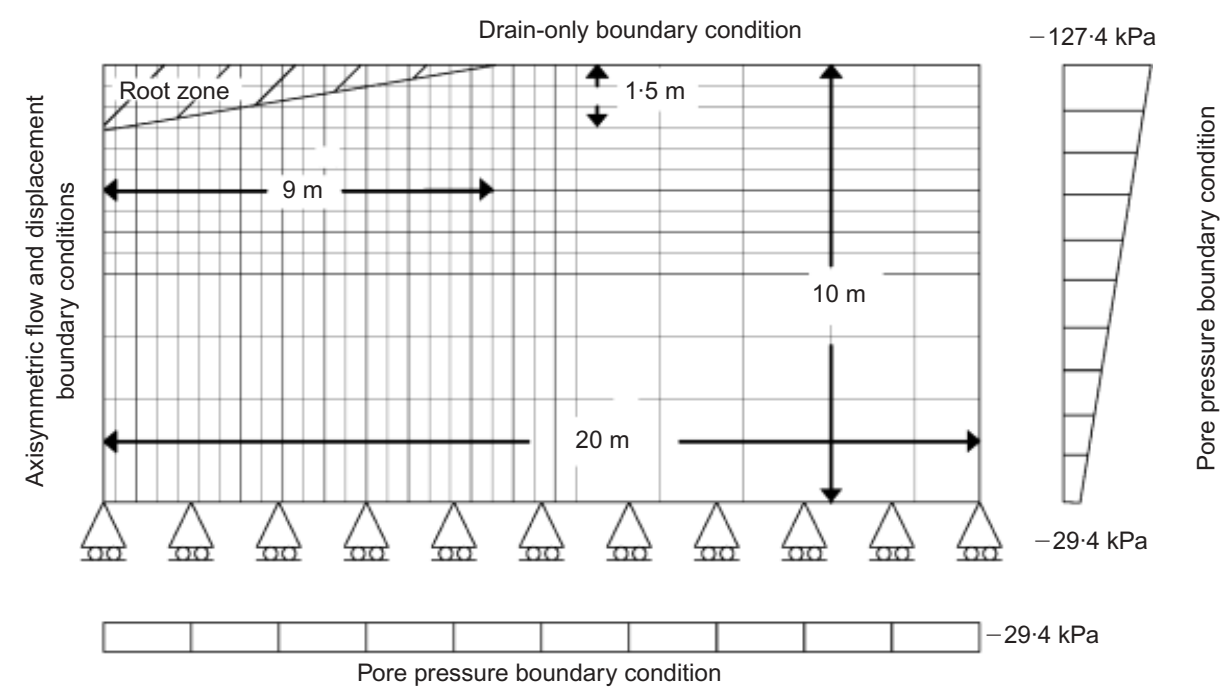

Fig. 19. Geometry and boundary conditions of case history 2

\begin{tabular}{|lcl|}
\hline Parameter & Value & Comments \\
\hline$r_{0}$ & $6 \mathrm{~m}$ & Radial coordinate of maximum root density point \\
$z_{0}$ & $0.50 \mathrm{~m}$ & Vertical coordinate of maximum root density point \\
$\beta_{\max }(t)$ & $25 \mathrm{~m}^{-2}$ & Taken from general shape or root suggested by Landsberg \\
$k_{3}$ & $0.0874 \mathrm{~m}^{-1}$ & As above \\
$k_{4}$ & 0.014 & Coefficient of potential transpiration distribution \\
$r_{\max }$ & $9 \mathrm{~m}$ & Estimated from field data \\
$z_{\max }$ & $1.5 \mathrm{~m}$ & Estimated from field data 28 \\
$k_{1}$ & 10 & Coefficient of vertical root distribution \\
$k_{2}$ & 0.30 & Coefficient of horizontal root distribution \\
$v$ & 0.30 & Typical value for clayey soils \\
$T_{\mathrm{P}}$ & $3 \mathrm{~mm} /$ day & Rate of potential transpiration \\
Passing \#200 & $55 \%$ & Typical value for Boulder clay \\
& & \\
\hline \multicolumn{2}{l}{ Table 5. Parameter values assumed in finite element analysis of case study 2} \\
\hline
\end{tabular}

have the same pattern as those monitored by Jaksa et al. ${ }^{27}$ As presented in Tables 2 and 5, the root length density distribution in the second case study is assumed to be more horizontal (flatter) than the first case study. As a result, the soil suction

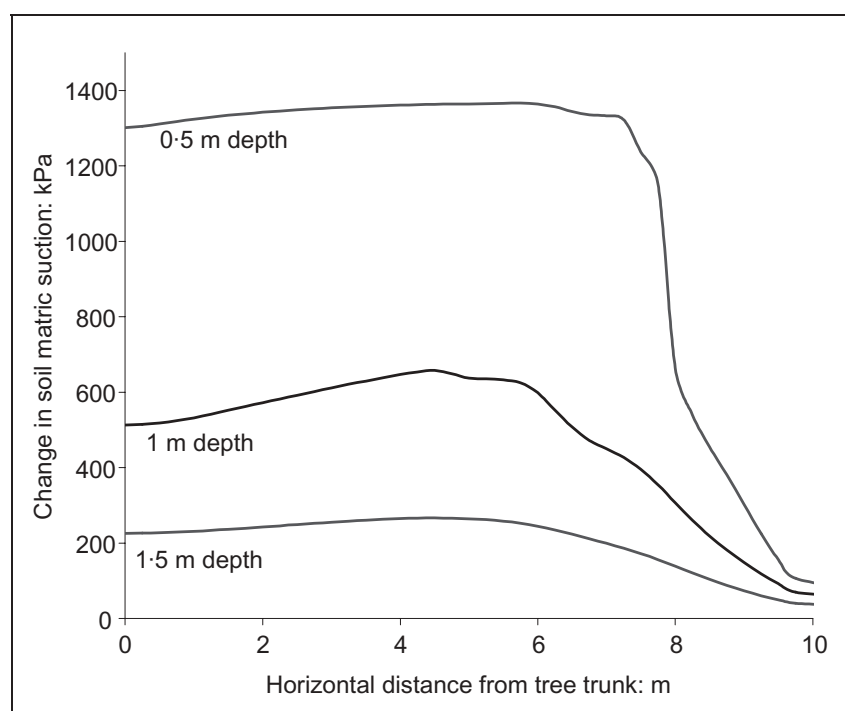

Fig. 20. Predicted soil matric suction in different depths reduction will also be flatter, as shown in Fig. 20. Fig. 21 shows a comparison between the field measurements and the predictions of the numerical model for moisture content reduction. The numerical results incorporating the authors' root water uptake model are in acceptable agreement with the field measurements reported by Biddle. ${ }^{28}$ According to Fig. 21, field measurements of moisture content reduction are noticeably different from the finite element predictions at approximately 6-8 $\mathrm{m}$ from the trunk. This is not surprising, given the simplicity of the assumptions with regard to the shape of the root zone. Furthermore, as the foliage alters the uniform distribution of rainfall, moisture content is expected to increase at the canopy edges (say approximately $6-8 \mathrm{~m}$ from the tree trunk), thereby probably contributing to the disparity between the field data and finite element predictions.

\section{CONCLUSIONS}

In this study, a mathematical model has been developed for predicting the rate of tree root water uptake. The main factors affecting the rate of root water uptake, namely (a) soil suction in the vicinity of roots, (b) root density and (c) potential transpiration, were taken into account to establish an appropriate expression for actual transpiration or root water uptake. The authors' numerical analysis was implemented in the ABAQUS finite element code to examine 


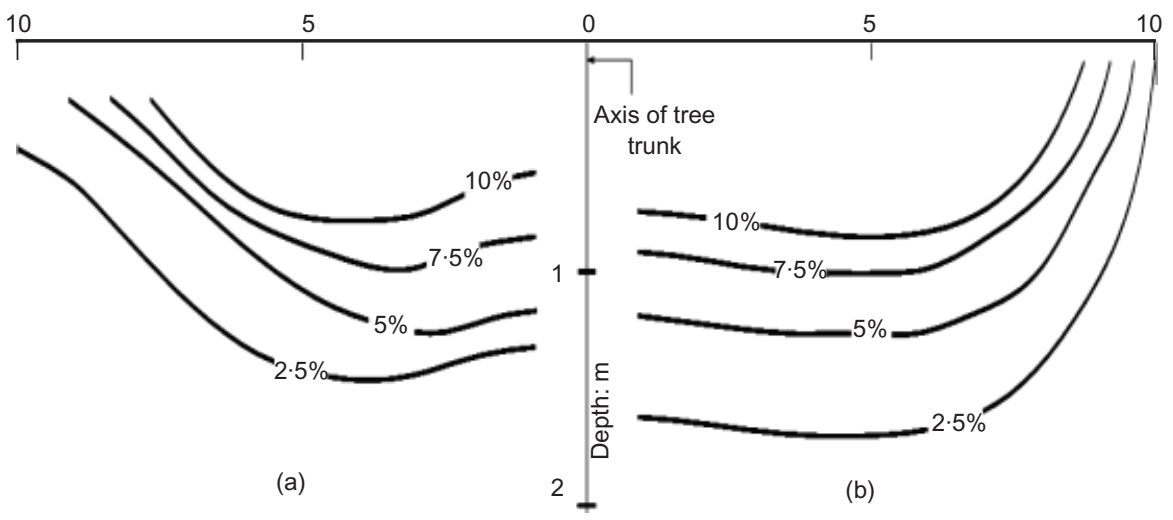

Fig. 21. Contours of volumetric soil moisture content reduction (\%) in vicinity of a lime tree: (a) Biddle; ${ }^{28}$ (b) current finite element analysism

the soil suction distribution and moisture content profile in the vicinity of a row of trees. The evaluation of the numerical results was successfully examined by comparing the ABAQUS output with a similar analysis performed by Fredlund and Hung. ${ }^{26}$ The disparity of results between the two methods was attributed to the distinctly different unsaturated soil model used by the authors in ABAQUS in comparison with the Fredlund and Hung approach. ${ }^{26}$ Then two case histories were considered to verify the authors' root water uptake distribution model.

In the first case study, the results of the predicted soil matric suction pressure around a single eucalyptus tree were compared with the available field data reported by Jaksa et $a l .{ }^{27}$ It was shown that the numerical analysis considering the authors' proposed model could predict the location of the maximum suction change away from the tree trunk as measured by Jaksa et al. ${ }^{27}$ However, direct comparison of suction values is not possible, because the proposed numerical model can predict only the matric suction changes, whereas the measurements obtained by Jaksa et al. ${ }^{27}$ were in total suction. Realistic comparison of suction changes is possible only if the matric suction component of the total suction is accurately known. The contours of ground settlement for this case study indicated that the maximum settlement at initial stages occurred near the point with the highest root water uptake rate. However, in the longer term (after 12 months), the maximum ground settlement takes place below the tree trunk.

In the second case study, the results of the predicted reduction in soil moisture content around a single lime tree were compared with the field measurements reported by Biddle. ${ }^{28}$ In spite of the uncertainties in the assumptions of some soil parameters, the actual tree root distribution and the atmospheric parameters, acceptable agreement was found between the measured and simulated soil moisture distributions.

Although more comprehensive field data are required to fully verify the root water uptake model presented in this paper, the numerical simulation described here is a promising tool for predicting the matric suction induced by tree roots within a soil matrix. A limitation to be noted is that the role of the root zone as a natural means of providing soil reinforcement has not been implemented in the current model.

\section{ACKNOWLEDGEMENTS}

This research has been sponsored by the Australian Cooperative Research Centre for Railway Engineering and Technologies (Rail-CRC). The contributions and feedback from various industry colleagues including Wayne Potter and David Christie are appreciated. The assistance of Dr Don Cameron (University of South Australia) is also acknowledged.

\section{REFERENCES}

1. Chок Y. H., KaggWa W. S., JaKSA M. B. and Griffiths D. V. Modelling the effects of vegetation on stability of slopes. Proceedings of the 9th Australian New Zealand Conference on Geomechanics, Auckland, 2004, 391-397.

2. OPERSTEIN V. and FrYDMAN S. The influence of vegetation on soil strength. Ground Improvement, 2000, 4, No. 2, $81-89$.

3. Docker B. B. and Hubble T. C. T. Strength and distribution of casuarinas glauca roots in relation to slope stability. In Geotechnical Engineering (Ho K. K. S. and LI K. S. (eds)). Swets \& Zeitlinger, Lisse, 2001, pp. 745-749.

4. Radcliffe D., Hayden T., Watson K., Crowley P. and PHILLIPS R. E. Simulation of soil water within the root zone of a corn crop. Agronomy Journal, 1980, 72, JanuaryFebruary, 19-24.

5. Feddes R. A., Kowalik P. J., KolinsKa-MalinKa K. and ZARADNY H. Simulation of field water uptake by plants using a soil water dependent root extraction function. Journal of Hydrology, 1976, 31, No. 1-2, 13-26.

6. Feddes R. A., KowaliK P. J. and ZaRAdNY H. Simulation of Field Water Use and Crop Yield, Simulation Monograph. Pudoc, Wageningen, 1978, pp. 9-30.

7. PRASAD R. A linear root water uptake model. Journal of Hydrology, 1988, 99, No. 3-4, 297-306

8. Molz F. J. Simulation of plant water uptake. In Modeling Waste Water Renovation by Land Application (ISKANDAR I. K. (ed.)). John Wiley, New York, 1981, pp. 69-91.

9. PERRochet P. Water uptake by plant roots: a simulation 
model. I: Conceptual model. Journal of Hydrology, 1987, 95, No. 1-2, 55-61.

10 NovaK V. Estimation of soil water extraction patterns by roots. Agricultural Water Management, 1987, 12, No. 4, 271-278.

11. KutileK M. and Nielsen D. R. Soil Hydrology. Catena Verlag, Cremlingen-Destedt, Germany, 1994.

12. Dobson M. C. and Moffat A. J. A re-evaluation of objections to tree planting on containment landfills. Waste Management and Research, 1995, 13, No. 6, 579-600.

13. SUDMEYER R. Tree Root Morphology in Alley System. Rural Industries Research and Development Corporation, Kingston, Australia, 2002, pp. 2-12, RIRDC Publication No. 02/024, RIRDC Project No. DAW-93A.

14. LANDSBERG J. J. Tree Water Use and its Implications in Relation to Agroforestry Systems. Rural Industries Research and Development Corporation (RIRDC), Kingston, Australia, 1999, pp. 1-24, Water and Salinity Issues in Agroforestry No. 5, RIRDC Publication No. 99/37, RIRDC Project No. CSM-4A.

15. Penman H. L. Natural evaporation from open water, bare soil and grass. Proceedings of the Royal Society of London, Series A, 1948, 193, 120-146.

16. Monteith J. L. Evaporation and environment. In The State and Movement of Water in Living Organisms (FoGG G. E. (ed.)). Academic Press, New York, 1965, pp. 204-234.

17. RIJTEMA P. E. An analysis of actual evapotranspiration. Agricultural Research Report, Pudoc, Wageningen, 1965, pp. 659-766.

18. LAi C. T. and KatUl G. The dynamic role of root-water uptake in coupling potential to actual transpiration. Advances in Water Resources, 2000, 23, No. 4, 427-439.

19. NIMAH M. N. and HANKS R. J. Model for estimating soil water, plant and atmospheric interrelations. I: Description and sensitivity. Proceedings of Soil Science Society of America, 1973, 37, No. 4, 522-527.

20. RichARDS B. G. A review of methods for the determination of the moisture flow properties of unsaturated soils. Tech. Memo. No. 5. Soil Science, 1967, 51, No. 1, 377-386.

21. Bishop A. W. The principle of effective stress. Teknish Ukebadk, 1959, 106, No. 39, 859-863.

22. Khalili N., Geiser F. and Blight G. E. Effective stress in unsaturated soils: review with new evidence. International Journal of Geomechanics, 2004, 4, No. 2, 115-126.

23. Lu N. and GRIFFITHS D. V. Profiles of steady-state suction stress in unsaturated soils. Journal of Geotechnical and Geoenvironmental Engineering, 2004, 130, No. 10, 1063 1076.

24. KhaBbaz M. H. An Effective Stress Theory Based Numerical Model for Flow and Deformation in Unsaturated Soils. PhD thesis, University of New South Wales, Sydney,1997.
25. ABAQUS, User Manual, version 6·4. ABAQUS Inc., Providence, RI, 2003.

26. FredLund D. G. and Hung V. Q. Prediction of volume change in an expansive soil as a result of vegetation and environmental changes. In Expansive Clay Soils and Vegetative Influence on Shallow Foundations (Vipulanandan C., Addison M. B. and Hansen M. (eds)). Geo Institute, ASCE, Houston, TX, USA, 2001, pp. 24-43.

27. JaKSA M. B., KaggWa W. S. and WoodBurn J. A. Influence of large gum trees on the soil suction profile in expansive soils. Australian Geomechanics Journal, 2002, 37, No. 1, 23-33.

28. BIDDLE P. G. Pattern of soil drying and moisture deficit in the vicinity of trees on clay soils. Géotechnique, 1983, 33, No. 2, 107-126.

29. GARDNER W. R. Some steady state solutions of the unsaturated moisture flow equation with application of evaporation from a water table. Soil Science, 1958, 85, No. 4, 228-232.

30. KnIGHT J. H. Tree Water Use and its Implications in Relation to Agroforestry Systems. Rural Industries Research and Development Corporation (RIRDC), Kingston, Australia, 1999, pp. 25-78, Water and Salinity Issues in Agroforestry No. 5, RIRDC Publication No. 99/37, RIRDC Project No. CSM-4A.

31. Dunin F. X., McIlroy I. C. and 0'Loughlin E. M. A lysimeter characterization of evaporation by eucalypt forest and its representativeness for the local environment. In The Forest-Atmosphere Interaction (HuTchinson B. A. and Hicks B. B. (eds)). Reidal, Dordrecht, 1985, pp. 271-291.

32. Zapata C. E., Houston W. N., Houston S. L. and WALSH K. D. Soil-water characteristic curve variability. In Advances in unsaturated geotechnics (SHACKEFORD C. D., Houston S. L. and ChAng N. Y. (eds)). Geo Institute, ASCE, Houston, TX, USA, 2000, pp. 84-124.

33. MCKeEn R. G. A model for predicting expansive soil behaviour. Proceedings of the 7th International Conference on Expansive Soils, Dallas, 1992, 1, 1-6.

34. BoZoZUK M. and BURN K. N. Vertical ground movement near elm trees. Géotechnique, 1960, 10, No. 1, 19-32.

35. PoWrie W., DAvies J. N. and Britto A. M. A cantilever retaining wall supported by a berm during temporary work activities. Proceedings of the ICE Conference on Retaining Structures, Cambridge, 1992, pp. 418-428.

36. Lehane B. M. and Simpson B. Modeling glacial till under triaxial conditions using a BRICK soil model. Canadian Geotechnical Journal, 2000, 37, No. 5, 1078-1088.

37. SKEMPTON A. W. Notes on compressibility of clays. Quarterly Journal of Geological Society, 1944, 100, No. 2, 119-135.

\section{What do you think?}

To comment on this paper, please email up to 500 words to the editor at journals@ice.org.uk

Proceedings journals rely entirely on contributions sent in by civil engineers and related professionals, academics and students. Papers should be 2000-5000 words long, with adequate illustrations and references. Please visit www.thomastelford.com/journals for author guidelines and further details. 